\title{
Analisis Dampak Rasio keuangan Perusahaan Terhadap Harga Saham Pada Perusahaan Yang Tercatat Pada JII
}

\author{
Astuti \\ Sekolah Tinggi Ilmu Ekonomi Sultan Agung \\ astuti@stiesultanagung.ac.id

\section{Elly Susanti} \\ Sekolah Tinggi Ilmu Ekonomi Sultan Agung \\ ellysusanti@stiesultanagung.ac.id

\section{Hery Pandapotan Silitonga} \\ Sekolah Tinggi Ilmu Ekonomi Sultan Agung \\ hery@stiesultanagung.ac.id
}

\begin{abstract}
Abstrak The research method uses qualitative data, secondary data sources, using documentation methods, classic data assumption test analysis techniques, coefficient of determination, hypothesis testing. The object of research in companies incorporated in the Jakarta Islamic Index in the period 2014 - 2018.The results of this study by F statistical tests show that all independent variables influence the dependent variable. In statistical test $t$ current ratio has a negative and significant effect on stock prices. Size and Debt to Asset Ratio influence and are not significant on stock prices. Return on Assets has a positive and significant effect on stock prices.
\end{abstract}

Kata Kunci current ratio, debt to asset ratio, size, harga saham

\section{PENDAHULUAN}

Suatu negara perkembangan ekonominya terlihat dari pasar modal yang dimilikinya (Amrah \& Elwisam, 2018). Pasar modal merupakan pasar dalam berinvestasi pada suatu Negara. Dalam melakukan investasi investor membutuhkan informasi mengenai harga saham ( $\mathrm{Fu}$ et al., 2020). Investasi dalam prinsip syariah juga sangat mengiurkan dalam menanamkan modal karena tidak kalah menguntungkan jika dibandingkan dengan kinerja rata rata saham pada umumnya. harga saham akan mempengaruhi keuntungan yang diperoleh oleh investor (Zaki et al., 2017). Penawaran dan permintaan faktor utama yang dapat mengubah harga saham (Singh \& Shakya, 2020). Menurut catatan Bursa Efek Indonesia pada tgl 17 September 2019, Jakarta Islamic Index mengalami pertumbuhan kinerja saham sebesar $1,85 \%$. Jika dibanding data kinerja IHSG data tersebut sudah baik karena IHSG hanya tumbuh berkisar 0,68 \%. (sumber :https://www.cnbcindonesia.com). Gambaran harga saham di JII periode 2014 - 2018, yaitu: 
Tabel 1

Pergerakan Harga Saham Periode 2014 - 2018

\begin{tabular}{|l|l|l|l|l|l|l|}
\hline \multirow{2}{*}{ No } & \multicolumn{1}{|c|}{ Nama Perusahaan } & \multicolumn{5}{|c|}{ Tahun } \\
\cline { 3 - 7 } & & 2014 & 2015 & 2016 & 2017 & 2018 \\
\hline 1 & PT Adaro Energy, Tbk & 1.040 & 515 & 1.695 & 1.860 & 1.215 \\
\hline 2 & PT AKR Corporindo, Tbk & 4.120 & 7.175 & 6.000 & 6.350 & 4.290 \\
\hline 3 & PT Astra International, Tbk & 7.425 & 6.000 & 8.275 & 8.300 & 8.225 \\
\hline 4 & PT BumiSerpongDamai, Tbk & 1.805 & 1.800 & 1.755 & 1.700 & 1.255 \\
\hline 5 & $\begin{array}{l}\text { PT Indofood CBP } \\
\text { SuksesMakmur, Tbk }\end{array}$ & 13.100 & 13.475 & 8.575 & 8.900 & 10.450 \\
\hline 6 & PT Vale Indonesia, Tbk & 3.625 & 1.635 & 2.820 & 2.890 & 3.260 \\
\hline 7 & $\begin{array}{l}\text { PT Indofood SuksesMakmur, } \\
\text { Tbk }\end{array}$ & 6.750 & 5.175 & 7.925 & 7.625 & 7.450 \\
\hline 8 & PT Kalbe Farma, Tbk & 1.830 & 1.320 & 1.515 & 1.690 & 1.520 \\
\hline 9 & $\begin{array}{l}\text { PT Perusahaan Gas Negara, } \\
\text { Tbk }\end{array}$ & 6.000 & 2.745 & 2.700 & 1.840 & 2.120 \\
\hline 10 & PT Semen Indonesia, Tbk & 16.200 & 11.400 & 9.175 & 9.900 & 11.500 \\
\hline 11 & PT SummareconAgung, Tbk & 1.520 & 1.650 & 1.325 & 945 & 805 \\
\hline 12 & $\begin{array}{l}\text { PT Telekomunikasi Indonesia, } \\
\text { Tbk }\end{array}$ & 2.865 & 3.105 & 3.980 & 4.440 & 3.750 \\
\hline 13 & PT United Tractors, Tbk & 17.350 & 16.950 & 21.250 & 35.400 & 27.350 \\
\hline 14 & PT Unilever Indonesia, Tbk & 32.300 & 37.000 & 38.800 & 55.900 & 45.400 \\
\hline 15 & PT WijayaKarya,Tbk & 3.680 & 2.640 & 2.360 & 1.550 & 1.655 \\
\hline
\end{tabular}

Sumber: Data Diolah (2020)

Dari tabel $1 \mathrm{di}$ atas diketahui bahwa harga saham mengalami yang mengalami fluktuasi selama periode 2014-2018. Dalam menentukan nilai saham dengan menggunakan analaisis teknik yang menggunakan data saham dari pasar (Hartono, 2017). Beberapa hal yang mengakibatkan harga saham berfluktuasi, seperti penelitian yang dilakukan (Elwisam, 2018), bahwa current rasio (CR) dan retutn on asset (ROA) berpengaruh negatif. Berbeda dengan penelitian (Zaki et al., 2017), (Priliyastuti \& Stella, 2016), dan (Octaviani \& Komalasarai, 2017), bahwa dengan tingkat CR dan ROA yang tinggi dan nilai Debt to Asset Ratio (DAR) menunjukkan tingkat kapabilitas perusahaan yang akan meningkatkan kepercayaan investor yang mengakibatkan tingginya harga saham. Sedangkan pada penelitian (Mentari, 2012), besar perusahaan maka akan unggul dalam kekayaan dan akan meningkatkan harga saham.Berdasarkan gap research tersebut rumusan masalah dalam peneltiian ini apakah pengaruh current ratio, size, debt to asset ratio,return on asset terhadap harga saham?

\section{LANDASAN TEORI}

\subsection{Signalling Theory}

Perusahaan melakukan aksi korporasi karena ingin melakukan investasi agar perusahaan tersebut bias going concern. Menurut (Manurung, 2012), menyatakan bahwa investasi yang dilakukan perusahaan membuat harga saham perusahaan meningkat. Oleh karenanya, agen perusahaan menerbitkan saham yang memberikan signal untuk disampaikan kepada pemegang sahamya itu pemilik saham diajak melakukan investasi lagi kepada perusahaan karena kinerja perusahaan dimasa mendatangakan mengalami kenaikan dengan investasi yang disampaikan (Siahaan et al., 2020).

\subsection{Harga Saham}


Informasi mengenai perusahaan di pasar saham tercermin dari seberapa besar harga saham perusahaan tersebut (Song, 2015). Harga tertinggi yang pembeli siap bayar untuk saham merupakan harga saham (Singh \& Shakya, 2020). Informasi harga saham mencerminkan keuntungan perusahaan (Zaki et al., 2017). Harga saham menggunakan harga penutupan (closing price), merupakan harga pada akhir periode akuntansi (Octaviani \& Komalasarai, 2017). Jika harga saham kelebihan, maka akan mengalami penurunan dan sebaliknya (Mentari, 2012).

\subsection{CURRENT RATIO (CR)}

Mengukut tingkat kemampuan perusahaan dalam membayar kewajiban lancar digunakan current ratio (Inrawan et al., 2020). Kemampuan perusahaan dikatakan baik apabila mampu membayar kewajibannya (Silitonga et al., 2017). Tingkat CR yang tinggi mengindikasikan perusahaan mempunyai tingkat pengembalian yang rendah, misalnya dana yang didepositokan. Rumus Current ratio adalah sebagai berikut:

$$
\text { Current Ratio }=\frac{\text { Asset Lancar }}{\text { Liabilitas Jangka Pendek }}
$$

Menurut Teori Trade Off menyatakan nilai CR mengindikasikan bahwa perusahaan mempunyai tingkat pengembalian yang rendah sehingga investor tidak tertarik melakukan pembelian sahamnya, hal ini akan mengakibatkan menurunkan harga saham. Tingginya tingkat CR suatu perusahaan tergantung dari jenis usaha perusahaan tersebut (Octaviani \& Komalasarai, 2017).

\subsection{SIZE (LN)}

Ukuran perusahaan suatu skala dalam mengkalsifikasikan besar kecilnya perusahaan (Panggabean et al., 2019). Jika perusahaan memiliki ukuran perusahaan (firm size)yang tinggi perusahaan tersebut lebih aman dalam melakukan kegiatan aktivitasnya (Eyer, 2018). Perusahaan digolongkan menjadi perusahaan besar atau kecil berdasarkan nilai ukuran perusahaannya (Subramaniam \& Wasiuzzaman, 2019). Ukuran perusahaan diukur dengan total aset (LN). Ukuran perusahaan yang besar mmemberikan daya tarik bagi investor (Mentari, 2012).

\subsection{DEBT TO ASSET RATIO (DAR)}

Dalam melunasi kewajiban lancarnya perusahaan diukur dengan rasio Debt to Asset Ratio (DAR) (Fiorensia et al., 2019). Dengan mengetahui nilai DAR perusahaan dapat mengukur kemampuan keuangannya dan dapat mencegah penggunaan dana dari utang untuk menambah aktifitasnya (Osazuwa \& Che-Ahmad, 2016). DAR suatu perusahaan menunjukkan besaran aset perusahaan yang menggunakan sana dari pihak eksternal. Hal ini akan mengakibatkan menurunkan minat investor dalam melakukan investasi (Elwisam, 2018). Rumus dari Debtt To Asset Ratio adalah :

$$
\text { Debt To Asset Ratio }=\frac{\text { Total Hutang }}{\text { Total Aset }}
$$


Jika perusahaan mampu membayar kewajibannya tanpa mengalami defisit keuangan, maka kinerja keuangannya baik dan akan menarik minat investor dalam melakukan investasi (Priliyastuti \& Stella, 2016).

\subsection{RETURN ON ASSET (ROA)}

Investor lebih tertarik dalam menanamkan investasi kepada yang aktifitasnya menggunakan dana perusahaan tidak melalui penggunaan utang (Jaisinghani \& Kanjilal, 2017). Kemampuan perusahaan dalam mengelola aset dalam memperoleh keuntungan digunakan rasio Return On Asset (ROA)(Silitonga et al., 2017). Dengan ROA yang tinggi perusahaan akan mampu membayarkan deviden kepada investor (Elwisam, 2018). Keadaan ini menunjukkan perusahaan sangat efektif menggunakan aset dalam memperoleh keuntungan, sehingga para investor sangat percaya bahwa perusahaan dapat memberikan deviden (Mentari, 2012).Semkain rendah rasio ini menunjukkan lemahnya kemampuan perusahaan dalam mendapatkan keuntungan menggunakan aset demikian sebaliknya (Hery, 2016).

Rumus dari Return on Asset adalah :

$$
\text { Return OnAsset }=\frac{\text { Laba Bersih }}{\text { Total Aset }}
$$

Semakin tingginya keuntungan perusahaan akan meningkatkan permintaan saham, dimanapeningkatan harga saham akan naik(Zaki et al., 2017).

\section{METODOLOGI PENELITIAN}

Data Kuantitatif dalam penelitian ini berupa CR, Size, DAR, ROA, dan Harga Saham (closing price). Data sekunder dijadikan sumber data dalam penelitian ini. Teknik pengumpulan data menggunakan metode dokumentasi. Teknik analisis data, uji asumsi klasik, koefesien determinasi, dan uji hipotesis. Perusahaan yang terdafatr di Jakarta Islamic Index di Bursa Efek Indonesia periode 2014-2018 berjumlah 47 perusahaan dijadikan populasi. Purposive sampling digunakan menentukan sampel penelitian. Dengan kriteria sebagai berikut:

\section{Tabel 2}

Kriteria Penentuan Sampel

Perusahaan yang tercatat di Jakarta Islamic Index berturut turut selama periode 2014 - 2018

Perusahaan menerbitkan Laporan Keuangan yang telah diaudit selama periode 2014-2018

Tabel 3

Sampel Penelitian

\begin{tabular}{|c|l|}
\hline No & \multicolumn{1}{|c|}{ Nama Perusahaan } \\
\hline 1 & PT Adaro Energy, Tbk \\
\hline 2 & PT AKR Corporindo, Tbk \\
\hline 3 & PT Astra International, Tbk \\
\hline 4 & PT BumiSerpongDamai, Tbk \\
\hline 5 & PT Indofood CBP SuksesMakmur, Tbk \\
\hline 6 & PT Vale Indonesia, Tbk \\
\hline 7 & PT Indofood SuksesMakmur, Tbk \\
\hline
\end{tabular}




\begin{tabular}{|c|l|}
\hline No & \multicolumn{1}{|c|}{ Nama Perusahaan } \\
\hline 8 & PT Kalbe Farma, Tbk \\
\hline 9 & PT Perusahaan Gas Negara, Tbk \\
\hline 10 & PT Semen Indonesia, Tbk \\
\hline 11 & PT SummareconAgung, Tbk \\
\hline 12 & PT Telekomunikasi Indonesia, Tbk \\
\hline 13 & PT United Tractors, Tbk \\
\hline 14 & PT Unilever Indonesia, Tbk \\
\hline 15 & PT WijayaKarya,Tbk \\
\hline
\end{tabular}

\section{HASIL PENELITIAN}

\subsection{UjiAsumsiKlasik}

Penyebaran data Harga Saham tidak berdistribusi normal. Oleh sebab itu, dalam pengolahan data ini dilakukan uji transformasi dengan menggunakan LN (Logaritma Natural).

\subsubsection{Uji Normalitas}

Tabel 4 Hasil Uji Normalitas

\begin{tabular}{|ll|r|}
\hline & & Unstandardized Residual \\
\hline Normal Parameters & & 74 \\
& Mean &, 0000000 \\
& Std. Deviation &, 83151990 \\
Most Extreme Differences & Absolute &, 095 \\
& Positive &, 082 \\
& Negative &,- 095 \\
Kolmogorov-Smirnov Z & &, 820 \\
Asymp. Sig. (2-tailed) & &, 512 \\
\hline
\end{tabular}

Sumber : Hasil Pengolahan SPSS,2020

Berdasarkan Tabel $4.2 \mathrm{di}$ atas diperoleh unstandarizedresidual >0,05, artinya variabel terdistribusi normal.

\subsubsection{Uji Multikoliniearitas}

Tabel 5: UjiMultikoliniearitas

\begin{tabular}{|l|r|r|l|}
\hline \multirow{2}{*}{ Model } & \multicolumn{2}{|l|}{ Collinearity Statistics } & Keterangan \\
\cline { 2 - 5 } & \multicolumn{1}{|l|}{ Tolerance } & \multicolumn{1}{l|}{ VIF } & \\
\hline 1 (Constant) & & & \\
LN_CR_X1 &, 357 & 2,797 & Tidak Terjadi Multikolineartitas \\
LN_Size_X2 &, 941 & 1,062 & Tidak Terjadi Multikolineartitas \\
LN_DAR_X3 &, 431 & 2,318 & Tidak Terjadi Multikolineartitas \\
LN_ROA_X4 &, 710 & 1,409 & Tidak Terjadi Multikolineartitas \\
\hline
\end{tabular}

Sumber : Hasil Pengolahan SPSS,2020 
Tabel 5 di atas, diperoleh nilai VIF CR 2,797, Size 1,062, DAR 2,318 dan ROA $1,409<10$, sehingga variabel tersebut bebas multikolinearitas.

\subsubsection{Uji Heteroskedastisitas}

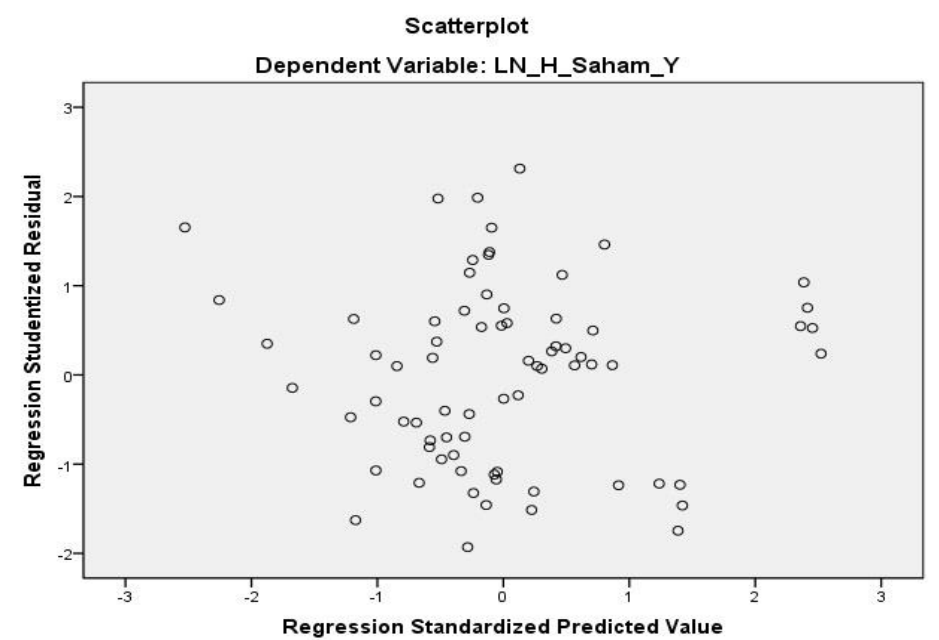

Sumber : Hasil Pengolahan SPSS,2020

\section{Gambar1}

UjiHeteroskedastisitas

Gambar grafik di atas menyebar secara acak, artinya tidak terjadi heteroskedastisitas

\subsubsection{Uji Autokorelasi}

Tabel 6

Uji Autokorelasi

Model Summary ${ }^{\mathrm{b}}$

\begin{tabular}{|c|c|c|c|c|c|c|c|c|c|c|}
\hline \multirow[b]{2}{*}{ Model } & \multirow[b]{2}{*}{$\mathrm{R}$} & \multirow[b]{2}{*}{$\begin{array}{c}\mathrm{R} \\
\text { Square }\end{array}$} & \multirow[b]{2}{*}{$\begin{array}{l}\text { Adjusted R } \\
\text { Square }\end{array}$} & \multirow{2}{*}{$\begin{array}{l}\text { Std. Error } \\
\text { of the } \\
\text { Estimate }\end{array}$} & \multicolumn{5}{|c|}{ Change Statistics } & \multirow[b]{2}{*}{$\begin{array}{l}\text { Durbin- } \\
\text { Watson }\end{array}$} \\
\hline & & & & & $\begin{array}{l}\text { R Square } \\
\text { Change }\end{array}$ & \begin{tabular}{|c|}
$\mathrm{F}$ \\
Change
\end{tabular} & df1 & df2 & $\begin{array}{c}\text { Sig. F } \\
\text { Change }\end{array}$ & \\
\hline 1 &, $644^{\mathrm{a}}$ &, 415 &, 381 & ,85528 &, 415 & 12,229 & 4 & 69 &, 000 & 2,353 \\
\hline
\end{tabular}

Sumber : Hasil Pengolahan SPSS,2020

Berdasarkan tabel 4.4 Durbin-Watson untuk data sebanyak 74 dan variabel bebas $\mathrm{k}=4$, maka akan diperoleh nilai $\mathrm{dL}=1,5112$, nilai $4-\mathrm{dL}=2,4888$, nilai $\mathrm{dU}=1,7383$ dan nilai 4-dU = 2,2617. Maka nilai uji Durbin-Watson pada tabel 4.3 di atas berada 4-dU< d $<4$-dL atau dapat dijelaskan bahwa 2,2617<2,353<2,4888, artinya tidak ada autokorelasi negatif. 


\subsection{Uji Hipotesis}

\subsubsection{Koefisien Determinasi $\left(\mathbf{R}^{2}\right)$}

\section{Tabel 7}

Koefisien Korelasi dan Determinasi

\begin{tabular}{|l|r|r|r|}
\hline & & & \\
Model & $\mathrm{R}$ & R Square & \multicolumn{2}{|c|}{ Adjusted R Square } \\
\hline 1 &, $644^{\mathrm{a}}$ &, 415 &, 381 \\
\hline
\end{tabular}

Sumber : Hasil Pengolahan SPSS,2020

Adjusted $R$ Square senilai 0,415, atau 41,5\% artinya harga saham dipengaruhi oleh CR, Size, DAR, ROA sebesar 41,5, dan sisanya 58,5\% dipengaruhi variabel diluar penelitian.

\subsubsection{Uji Simultan (Uji F)}

\section{Tabel8}

Uji F

ANOVA $^{b}$

\begin{tabular}{|ll|r|r|r|r|r|}
\hline Model & & Sum of Squares & df & Mean Square & F & Sig. \\
\hline 1 & Regression & 35,782 & 4 & 8,946 & 12,229 &, $000^{\mathrm{a}}$ \\
& Residual & 50,474 & 69 &, 732 & & \\
& Total & 86,256 & 73 & & & \\
\hline
\end{tabular}

a. Predictors: (Constant), LN_ROA_X4, LN_DAR_X3, LN_Size_X2, LN_CR_X1

b. Dependent Variable: LN_H_Saham_Y

Sumber : Hasil Pengolahan SPSS,2020

Uji F, dengan nilai sig 0,000 diperoleh seluruh variabel independen (CR, Size, DAR, dan ROA) berpengaruh signifikan terhadap Harga saham.

\subsubsection{Uji Statistik $t$}

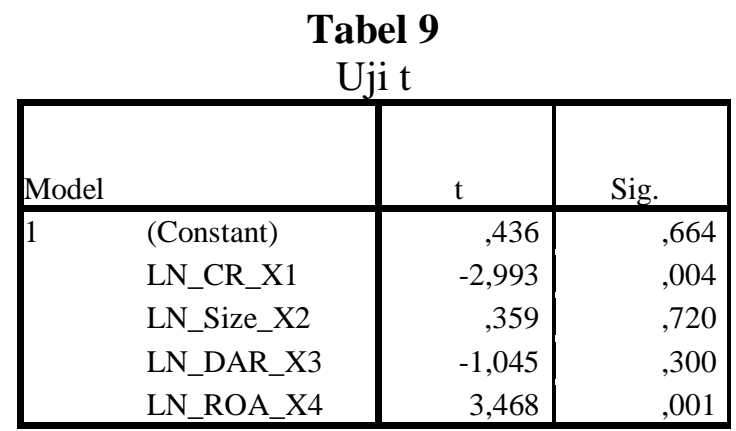

Sumber : Hasil Pengolahan SPSS,2020

Berdasarkan tabel 9, didapatkan nilai dengan kesimpulan sebagai berikut:

(1) CR nilai thitung sebesar $-2,993$, dan nilai sig 0,004 , artinya CR berpengrauh negatif, peningkatkan CR akan menurunkan harga saham.

(2) Size nilai $t_{\text {hitung }}$ sebesar 0,359, dan nilai sig 0,720 (>0,05), artinya Size berpengaruh positif, artinya dengan meningkatkan size maka harag saham akan meningkat. 


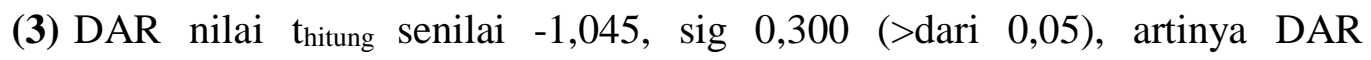
berpengaruh negatif, peningkatkan nilai DAR akan menurunkan harga saham.

(4) ROA nilai thitung senilai 3,468 , nilai sig $0,001(<0,05)$, artinya ROA berpengaruh positif, dengan tingkat ROA yang tinggi maka harga saham perusahaan akan meningkat.

\section{KESIMPULAN}

Berdasarkan penelitian yang telah dilakukan, dan dijabarkan oleh peneliti, kesimpulan, ialah:

1. CR, Size, DAR, ROA mempengaruhi harga saham sebesar $41,5 \%$

2. Peningkatan $\mathrm{CR}$ akan menurunkan harga saham, karena investor melihat perusahaan tidak mampu menggunakan dana yang telah ada untuk menambah aktifitasnya

3. Tingkat ukuran perusahaan meningkatkan harga perusahaan, dimana investor akan tertarik dengan ukuran perusahaan yang tinggi. Perusahaan tersebut dianggap mampu memperoleh keuntungan.

4. Nilai DAR yang tinggi menurunkan harga saham, karena semkain tinggi utang perusahaan akan meningkatkan beban, seperti beban bunga.

5. Tingkat ROA yang tinggi meningkatkan harga saham, karena dengan tingkat keuntungan yang tinggi perusahaan akan mampu membayarkan deviden.

\section{DAFTAR PUSTAKA}

Amrah, R. Y., \& Elwisam. (2018). Pengaruh Current Ratio, Return on Assets, Debt to Equity Ratio dan Total Assets Turnover Terhadap Harga Saham pada Perusahaan LQ45 Tahun 2013-2015. Jurnal Ilmu Manajemen, 14(1), 46-62.

Elwisam, R. Y. A. (2018). Pengaruh Current Ratio, Return on Assets, Debt to Equity Ratio dan Total Assets Turnover Terhadap Harga Saham pada Perusahaan LQ45 Tahun 2013-2015. Jurnal Ilmu Manajemen, 14(2), 26-42.

Eyer, J. (2018). The effect of firm size on fracking safety. Resource and Energy Economics, 53, 101-113. https://doi.org/10.1016/j.reseneeco.2018.02.006

Fiorensia, F., Siregar, L., Nainggolan, C. D., \& Silitonga, H. P. (2019). Dampak Quick Ratio Dan Debt To Equity Ratio Terhadap Price Earning Ratio Pada Pt Merck, Tbk. Financial: $\quad$ Jurnal Akuntansi, 5(2), 91-98. https://doi.org/10.37403/financial.v5i2.114

Fu, J., Wu, X., Liu, Y., \& Chen, R. (2020). Firm-specific investor sentiment and stock price crash risk. Finance Research Letters, August 2019, 101442. https://doi.org/10.1016/j.frl.2020.101442

Hartono, J. (2017). Teori Portofolio dan Analisis Investasi (Sebelas). BPFE. 
Hery. (2016). Financial Ratio For Business. Grasindo.

Inrawan, A., Jubi, Silitonga, H. P., \& Sudirman, A. (2020). PENGARUH LIKUIDITAS DAN SOLVABILITAS TERHADAP RENTABILITAS MODAL SENDIRI PADA PKPRI DI KABUPATEN SIMALUNGUN. 5(1), 1-15.

Jaisinghani, D., \& Kanjilal, K. (2017). Non-linear dynamics of size, capital structure and profitability: Empirical evidence from Indian manufacturing sector. Asia Pacific Management Review, 22(3), 159-165. https://doi.org/10.1016/j.apmrv.2016.12.003

Manurung, A. H. (2012). Konsep dan Empiris Teori Investasi. PT Adler Manurung Press.

Mentari, R. I. (2012). Dampak ROE, NPM, dan Ukuran Perusahaan terhadap Harga Saham Perusahaan yang Tercantum dalam Indeks LQ45 BEI pPeriode 2010-2012. Jurnal Akuntansi, UDINUS, 1-17.

Octaviani, S., \& Komalasarai, D. (2017). PENGARUH LIKUIDITAS, PROFITABILITAS, dan SOLVABILITAS TERHADAP HARGA SAHAM (Studi Kasus pada Perusahaan Perbankan yang Terdaftar di Bursa Efek Indonesia). Jurnal Akuntansi., 3(2), 77-89.

Osazuwa, N. P., \& Che-Ahmad, A. (2016). The moderating effect of profitability and leverage on the relationship between eco-efficiency and firm value in publicly traded Malaysian firms. Social Responsibility Journal, 12(2), 295-306. https://doi.org/10.1108/SRJ-03-2015-0034

Panggabean, V. D. Y., Inrawan, A., Silitonga, H. P., \& Sembiring, L. D. (2019). DAMPAK STRUKTUR ASET DAN UKURAN PERUSAHAAN TERHADAP STRUKTUR MODAL. 4328.

Priliyastuti, N., \& Stella. (2016). Pengaruh Current Ratio Dan Debt To Equity Ratio Terhadap Return On Assets. Widyakala Journal, 3(1), 23. https://doi.org/10.36262/widyakala.v3i0.21

Siahaan, Y., Susanti, E., \& Sudirman, A. (2020). Effect of firm characteristics on firm value through triple bottom line disclosure: Pharmaceutical companies listed on Indonesia stock exchange. International Journal of Scientific and Technology Research, 9(2), 2228-2234.

Silitonga, H. P., Siregar, L., Tarigan, P., \& Inrawan, A. (2017). PENGARUH LIKUIDITAS DAN LEVERAGE TERHADAP PROFITABILITAS PADA PT JAPFA COMFEED INDONESIA , TbK . YANG TERDAFTAR DI BURSA EFEK INDONESIA. 3(1), 1-9.

Singh, A., \& Shakya, S. (2020). ScienceDirect ScienceDirect Analysis of look back period for stock price prediction with Analysis of look back period price prediction with RNN variants : A case study for on stock banking sector of NEPSE RNN variants : A case study on banking sector of N. Procedia Computer Science, 167(2019), 788-798. https://doi.org/10.1016/j.procs.2020.03.419

Song, L. (2015). Accounting disclosure, stock price synchronicity and stock crash risk: An emerging-market perspective. International Journal of Accounting and 
Information Management, 23(4), 349-363. https://doi.org/10.1108/IJAIM-022015-0007

Subramaniam, V., \& Wasiuzzaman, S. (2019). Geographical diversification, firm size and profitability in Malaysia: A quantile regression approach. Heliyon, 5(10). https://doi.org/10.1016/j.heliyon.2019.e02664

Zaki, M., Islahuddin, \& Shabri, M. (2017). Pengaruh Profitabilitas, Leverage Keuangan dan Ukuran Perusahaan Terhadap Harga Saham (Studi Pada Perusahaan Manufaktur Yang Terdaftar di Bursa Efek Indonesia Periode 2005-2014). Jurnal Megister Akuntansi, 6(2), 58-66. http://jurnal.unsyiah.ac.id/JAA/article/view/8969 